\title{
Ortaokul Öğrencilerinin Özel Etüt Merkezlerine Yönelik Görüşleri*
}

\section{Views of Middle School Students about Private Tutoring Centers}

\author{
Kader BiRINCI KONUR**
}

Öz. Bu çalışmada, ortaokul öğrencilerinin özel etüt merkezlerine yönelik görüşlerinin incelenmesi ve bu görüşlerin cinsiyet ve sınıf düzeyine göre farklılık gösterip göstermediğinin belirlenmesi amaçlanmıştır. Çalışma iki aşamada yürütülmüştür. Illk aşamada açık uçlu maddelerden oluşan bir anket 50 öğrenciye uygulanmıştır. Çalışmanın ikinci bölümünde ise anketten elde edilen verilerle bir 5 'li likert tipi 24 maddelik görüş ölçeği oluşturulmuştur. Ölçek 150 ortaokul öğrencisine uygulanmıştır. Çalışmada, öğrencilerin etüt merkezlerine yönelik görüşlerinin bazı değişkenlere bağlı olarak farklılaştığı ortaya konulmuştur. Etüt merkezleri okul derslerine destek sağlayan, öğrencilerin boş zamanlarını dolduran, merkezi sınavlara hazırlayan ve öğrencilerin rekabet gücünü artıran kuruluşlar olarak değerlendirilmiştir. Öğrencilerin etüt merkezlerine yönelik görüşlerinin cinsiyet ve sınıf düzeyine göre farklılaşmadığı ortaya konulmuştur.

Anahtar Kelimeler: Etüt merkezi, ortaokul öğrencileri, öğrenci görüşleri.

\begin{abstract}
In this study, it is aimed to examine the views of middle school students about private tutoring centers and to determine whether these opinions differ according to gender and grade. The study was conducted in two stages. In the first stage, a questionnaire composed of open ended items was applied to 50 students. In the second part of the study, five-point likert-type scale with 24 items was design in the questionnaire. The scale was applied to 150 middle school students. In the study, it was revealed that the opinions of the students towards the tutoring centers differ depending on some variables. The private tutoring centers were evaluated as institutions that provide support for school lectures, fill up their leisure time, prepare for central exams, and increase the competitive power of their students. The opinions of the students about the private tutoring center have not been differentiated according to gender and grade level.
\end{abstract}

Keywords: Private tutoring centers, middle school students, views of students.

\section{Ayşegül DEDE ${ }^{* * *}$}

\section{Toplumsal Mesaj.}

Türkiye'de 2011 yilında kurulan ve 2017 yilında kapatılmasına karar verilen özel öğrenci etüt merkezleri hakkındaki tartışmalar devam etmektedir. Bu çalışmada, öğrencilerin etüt merkezlerine yönelik görüşlerinin belirlenmesi amaçlanmıştır. Çalışmanın sonucunda, öğrencilerin etüt merkezlerine okula destek sağlaması ve merkezi sınavlarda daha başarııı olmak amacıyla gittikleri belirlenmiştir.

Public Interest Statement. Discussions on private tutoring centers established in Turkey in 2011 and decided to be closed in 2017 are ongoing. In this study, it is aimed to determine the opinions of the students towards the private tutoring centers. As a result of the study, it has been determined that the students go to the private tutoring centers in order to be more successful at examinations.

\footnotetext{
* Bu çalışma 11- 14 Mayıs 2017 tarihlerinde Ordu Üniversitesinde düzenlenen IX. Uluslararası Eğitim Araştırmaları Kongresinde sözlü bildiri olarak sunulmuştur.

${ }^{* *}$ Yrd. Doç. Dr., Recep Tayyip Erdoğan Üniversitesi, Eğitim Fakültesi, Fen Bilgisi Eğitimi Bölümü, kader.konur@erdogan.edu.tr

${ }^{* \star \star}$ Doç. Dr., Recep Tayyip Erdoğan Üniversitesi, Eğitim Fakültesi, Fen Bilgisi Eğitimi Bölümü, ahmet.tekbiyik@erdogan.edu.tr

${ }^{* * * *}$ Recep Tayyip Erdoğan Üniversitesi

Birinci Konur, K., Tekbıyık, A ve Dede, A. (2017). Ortaokul Öğrencilerinin Özel Etüt Merkezlerine Yönelik Görüşleri. Sakarya University Journal of Education, 7(3), 611-624
} 


\section{GiRiş}

Eğitim kurumlarının görev ve sorumluluklarının başında, öğrencileri öğretim programlarında tanımlanan hedeflere ulaştırmak gelmektedir. Ancak bazı nedenlerle bu hedeflerin gerçekleştirilemediği durumlar görülebilmektedir. Kalabalık sınıflar, yetersiz materyaller, öğretmen niteliği ve üst öğrenime geçmede kullanılan merkezi sınavlardaki başarı beklentisinin yüksek olması gibi gerekçeler ebeveynleri okul dışındaki arayışlara yönlendirebilmektedir (Ünsal ve Korkmaz, 2016). Bu ihtiyacı karşılayacak en önemli kuruluşların başında özel kurslar gelmektedir.

Türkiye'de 2011 yılında yayımlanan Milli Eğitim Bakanlığı Özel Öğrenci Etüt Eğitim Merkezleri Yönetmeliği uyarınca "Özel Öğrenci Etüt Merkezi" adı verilen kurslar kurulmaya başlanmıştır. Özel öğrenci etüt eğitim merkezi; öğrencilerin, derslerine çalışmalarına, ödev ve projelerini hazırlamalarına yardımcı olan, ilgi, istek ve yetenekleri doğrultusunda çeşitli faaliyetlerin yürütüldüğü özel öğretim kurumları olarak tanımlanmasa da, ilkokuldan lise düzeyine kadar farklı ders ve uygulama imkânlarını kayıtlı öğrencilerine sunmaktadır. Yetiştirme kurslarının yanında, son dönemlerde yaygınlaşan "Etüt Merkezleri" bu kurslara alternatif özel ve paralı bir faaliyet biçimi olarak görülebilir. Bu merkezler özellikle anne-babası tüm gün çalışan ve ikili öğrenim gören çocuklar için tasarlanmış; ancak yaygınlaştıkça etkinlik alanları genişlemiştir. Bu merkezler, öğrencilerin bazı derslerdeki başarısızlıklarını gidermek, ev ödevlerini ve projelerini yapmalarına yardımcı olmak ve sınavlara hazırlamak gibi etkinlikleri de yapmaktadır (Köse, 2013; Şimşek ve Şimşek, 2015). Bununla birlikte yaşanan süreçte 687 Sayılı Kanun Hükmünde Kararname ile 5580 sayılı Özel Öğretim Kurumları Kanununda yapılan değişiklikte 2011 yılında eğitim sistemimize dâhil olan etüt eğitim merkezleri 2017 yılında kapatılarak, faaliyet gösteren 2006 etüt merkezine dönüşüm hakkı tanınmıştır. 5580 sayılı Özel Öğretim Kurumları Kanunu'nda yer alan, 'öğrenci etüt eğitim merkezleri' ibaresi ve tanımı yürürlükten kaldırılarak, yerine 'sosyal etkinlik merkezleri' ibaresi eklenmiştir. KHK ile daha önce kanunda olmayan, "sosyal etkinlik merkezlerinin" açılmasına izin verilmiştir. Bu merkezlerde öğrencilerin sosyal, kültürel ve sanatsal faaliyetleri yürütebilmesi planlanmıştır. Bu kararla, ilkokul ve ortaokul öğrencilerinin, okul dışında herhangi bir takviye kursuna gitmesine izin verilmeyeceği görülmektedir (URL 2).

Türkiye' de yapılan bazı araştırmalar, bu kurumlardaki eğitimi alarak giriş sınavlarına giren öğrencilerin, eğitimi almayan öğrencilere kıyasla daha başarılı olduğunu ortaya koymaktadır (Baştürk, 2003; Morgil, Yılmaz ve Geban, 2001; Okur ve Dikici, 2004). Ayrıca bu kurumlara devam etmiş öğrencilerin sınavdaki başarılarının yüksek düzeyde olduğu belirtilmektedir (Kanat, 2004). Dünyanın birçok ülkesinde örgün eğitimle yetinmeyen aileler, çocukları için okul dışında ek destek sağlamak amacıyla yeni alternatifler aramaktadırlar. ABD başta olmak üzere bütün dünyada destek eğitim sistemlerine ihtiyaç duyulmaktadır (URL1). İngiltere, Almanya ve Fransa gibi yerlerde de etüt merkezine benzer kurumlara rastlanmaktadır; ancak bunlar Türkiye'de ve uzak doğu ülkelerinde olduğu kadar yaygın değildir. Bunun en önemli nedenleri, bu ülkelerde eğitim süreci içerisindeki basamaklar arasında etkin bir işleyişin bulunması, yönlendirmenin uzun bir sürece yayılması ve alternatif eğitim olanaklarının özellikle mesleki eğitime yönlendirmede büyük bir başarıyla gerçekleştirilmesidir (Arslan, 2004; URL 3).

Öğrencilerin akademik başarılarını artırmayı ve sosyal yönden desteklemeyi amaçlayan etüt merkezleri hem öğrencinin hem velinin yükünü hafifletmektir. Günümüzde genellikle çalışan anne ve babaların çocuğu okuldan çıktıktan sonra yalnız başına kalmasının ya da ebeveynleri eve dönünceye kadarki süreyi bilgisayar başında veya televizyon izleyerek genelde zararlı olan etkinliklerle geçirebildikleri belirtilmektedir. Ayrıca akşam saatlerinin veli ve öğrenci açısından ev ödevleri için verimli olmadığı vurgulanmaktadır (URL 4; Şimşek ve Şimşek, 2015). Bu gibi durumlarda etüt merkezleri veliler için bir çözüm olarak düşünülmektedir. Günümüzün çağdaş öğrenme yaklaşımlarıyla öğretmenlerin görev ve sorumluklukları yeniden tanımlanmıştır. Bu tanımlamada öğretmenlere bilgiyi sunan ve aktaran değil, öğrenme sürecinde rehber olma sorumluluğu verilmiştir (Akkoyunlu, 1998; Çeken, 2009; Türkoğlu, 2011). Fakat okuldaki sınıfların kalabalık olması, derslerin yoğunluğu, programın yetiştirilme çabası gibi çeşitli sebeplerle 
beklenilen öğrenme çıktılarına erişilemeyebilmektedir. Bu bağlamda etüt merkezleri bir alternatif çözüm olarak değerlendirilebilir.

Literatür incelendiğinde, etüt merkezlerine duyulan intiyaca ilişkin çalışmalara rastlanmamakla birlikte bu intiyacın; okullardaki eğitimin yapılan sınavlara göre yetersizliği (Gümüş, 2014), etüt merkezlerindeki sınıflarda okullardaki sınıflara göre öğrenci sayısının az olması (Tansel ve Bircan, 2004), kullanılan materyallerin fazla olması (Tansel ve Bircan, 2004), öğrenci-öğretmen ilişkilerinin daha yoğun olması (Tansel ve Bircan, 2004), daha nitelikli eğitim alma arayışı (Duran, Düzgün ve Duran, 2014; Büyükköse, 2010) gibi sebeplerden kaynaklandığı düşünülebilir.

Etüt merkezleri hakkında ortaya konulan görüşlerin, yetişkinlerin bakış açısıyla oluşturulduğu ve bu merkezlere devam öğrencilerin bakış açısını yansıtmadığı görülmektedir. Bu bağlamda özel etüt merkezlerine devam eden öğrencilerin bu merkezlere yönelik görüşlerinin araştırılmasının alan yazına katkı sağlayacağı öngörülmektedir. Ayrıca bu çalışma, daha sonradan kapatılmasına karar verilen etüt merkezlerinin, öğrenci ve veli ihtiyaçlarını ne şekilde karşıladığı ve bu ihtiyacı karşılayacak yeni oluşumların (sosyal etkinlik merkezleri vb.), çalışmadan ortaya çıkacak sonuçlarla yapılandırılması bakımından önem arz etmektedir.

\subsection{Amaç}

Bu çalışmada, ortaokul öğrencilerinin etüt merkezlerine yönelik görüşlerinin incelenmesi ve bu görüşlerin cinsiyet ve sınıf düzeyine göre farklıılk gösterip göstermediğinin belirlenmesi amaçlanmıştır.

Bu amaçla aşağıda belirtilen araştırma sorularına yanıt aranmaktadır:

1. Ortaokul öğrencilerinin etüt merkezlerine yönelik görüşleri nasıldır?

2. Ortaokul öğrencilerinin etüt merkezine yönelik görüşleri, cinsiyetlerine göre farklılık göstermekte midir?

3. Ortaokul öğrencilerinin etüt merkezine yönelik görüşleri bulundukları sınıf düzeyine göre farklılık göstermekte midir?

\section{YÖNTEM}

Tarama modelinde yürütülen çalışma iki aşamada gerçekleştirilmiştir. ilk aşamada açık uçlu maddelerden oluşan bir anket İstanbul ilindeki bir etüt merkezinde 2016-2017 eğitim-öğretim yılında öğrenim gören 50 öğrenciye uygulanmıştır. İkinci aşamada ise anketten elde edilen maddelerden bir ölçek formu oluşturularak uygulanmıştır.

\section{1 Örneklem}

Araştırmanın örneklemini, 2016-2017 eğitim öğretim yılında Rize ilindeki bir etüt merkezinde eğitim gören 6. ve 7. sınıflardan 57, Çayeli ilçesindeki bir etüt merkezinde eğitim gören 5, 6. ve 7. sınıflardan 45 ve İstanbul ili Küçükçekmece ilçesindeki bir etüt merkezinde eğitim gören 6 . ve 7 . sınıflardan 48 olmak üzere 150 öğrenci oluşturmuştur. Örneklemin belirlenmesinde, hedef kitleye ulaşma güçlüğü göz önünde bulundurularak kolay ulaşılabilirlik esas alınmıştır. Çalışmanın ilk aşamasına katılan 50 öğrenci, 150 kişilik örnekleme dâhil değildir. Örneklemin dağılımı Tablo 1'de sunulmuştur.

Tablo 1. Çalışma Grubunun Cinsiyet Ve Sınıf Düzeylerine Göre Dağılımı

\begin{tabular}{|c|c|c|c|c|c|c|}
\hline & \multicolumn{2}{|c|}{ Kız } & \multirow{2}{*}{$\begin{array}{c}\text { Erkek } \\
\mathrm{f}\end{array}$} & \multicolumn{3}{|c|}{ Toplam } \\
\hline & $f$ & $\%$ & & $\%$ & f & $\%$ \\
\hline 5.sinıf & 13 & 86.7 & 2 & 13.3 & 15 & 100.0 \\
\hline 6.sinıf & 24 & 46.2 & 28 & 53.8 & 52 & 100.0 \\
\hline 7.sinif & 38 & 45.8 & 45 & 54.2 & 83 & 100.0 \\
\hline
\end{tabular}




\subsection{Veri Toplama Yöntemi}

Ortaokul öğrencilerinin etüt merkezlerine yönelik görüşlerini belirlemek amacıyla öncelikle açık uçlu sorulardan oluşan bir anket hazırlanmıştır. Anket İstanbul ilindeki bir etüt merkezinde 20162017 eğitim-öğretim yılında öğrenim gören 50 öğrenciye uygulanmıştır. Ankette etüt merkezlerini tercih etme nedenleri, etüt merkezleri hakkındaki görüşleri vb. hususlar hakkında öğrencilere sorular yöneltilmiştir. Bu uygulamadan elde edilen veriler doğrultusunda 28 maddelik "Etüt Merkezlerine Yönelik Görüş Ölç̧eği" oluşturulmuştur. Ölçeğin 28 maddesi "önem, gereksinim, beklenti ve ilgi" olmak üzere dört alt boyuta ayrılmıştır. Bu süreçte ölçek maddelerinin kapsam geçerliğinin incelenmesi için Lawshe (1975) tekniğinden yararlanılmıştır. Lawshe tekniğinde, en az 5 en fazla 40 uzmanın görüşü alınmaktadır. Uzmanların her bir maddeye yönelik görüşleri; "madde hedeflenen yapıyı ölçmeye uygundur', "madde yapı ile ilişkili ancak yetersizdir' ya da ,"madde hedeflenen yapıyı ölçmez" şeklinde derecelendirilmektedir (Yurdugül, 2005). Belirtilen derecelendirmeye göre Kapsam Geçerliği Oranı (KGO) hesaplanmaktadır. Bu çalışmada 5 uzman akademisyenin görüşü alınmıştır. Beş uzman için KGO'nun en az 0.99 olması gerektiği belirtilmektedir (Veneziano ve Hooper, 1997). Uzmanların görüşlerine göre sadece "madde hedeflenen yapıyı ölçmeye uygundur" şeklinde belirtilen maddelerin ölçekte yer almasına karar verilmiştir. Bu sayede KGO'nun 1.00 olması sağlanmıştır. Buna göre 4 madde ölçekten çıkarılarak 24 maddelerik nihai form elde edilmiştir. Bununla birlikte uzmanların ölçeğe dahil edilen maddelere ilişkin, maddenin anlaşılabilirliği, hedef kitleye uygunluğu bakımından önerileri de değerlendirilmiştir.

Ölçek, "kesinlikle katılıyorum" 5, "katılıyorum" 4, "orta düzeyde katılıyorum" 3, "katılmıyorum" 2 ve "kesinlikle katılmıyorum" 1 puan şeklinde derecelendirilmiştir. Ölçeğin tümü için iç tutarlılık katsayısı $a=0,87$; beklenti boyutu için $a=0.74$, önem boyutu için $a=0.59$, ilgi boyutu için $a=0.70$, gereksinim için $a=0.65$ olarak hesaplanmıştır.

\subsection{Verilerin Analizi}

Elde edilen verilerin analizinde SPSS paket programı kullanılmıştır. Veriler madde ve alt boyut bakımından betimsel istatistiklerle temsil edilmiş ve grup karşılaştırmalarında t testi ve tek yönlü ANOVA' dan yararlanılmıştır.

\section{BULGULAR}

Çalışmada elde edilen bulgular bu bölümde alt problemlere göre sınıflandırılarak aşağıda sunulmuştur.

\subsection{Birinci Alt Probleme ilişkin Bulgular}

3.1.1. Etüt Merkezlerine Yönelik Görüş Ölçeği Beklenti Boyutuna illişkin Dağılımlar

Öğrencilerin, Etüt Merkezlerine Yönelik Görüş Ölçeğinin Beklenti boyutuna ilişkin maddelere verdikleri yanıtların yüzdelik dağılımları Tablo 2'de sunulmuştur.

Tablo 2. Beklenti Boyutuna Iliş̧kin Maddelerin Yüzdelik Dağılımları

\begin{tabular}{llllll}
\hline $\begin{array}{l}\text { Maddeler } \\
\text { Etüt merkezine... }\end{array}$ & $\mathbf{1}$ & $\mathbf{2}$ & $\mathbf{3}$ & $\mathbf{4}$ & $\mathbf{5}$ \\
\hline 1-ìyi bir eğitim görmek için gidiyorum. & 5.3 & 0.7 & 2.0 & $\mathbf{2 4 . 7}$ & $\mathbf{6 7 . 3}$ \\
2-TEOG sınavından yüksek puan alabilmek için gidiyorum. & 8.0 & 4.0 & 4.7 & $\mathbf{1 1 . 3}$ & $\mathbf{7 2 . 0}$ \\
3-Arkadaşlarımdan daha iyi puan almak için gidiyorum. & 16.7 & 16.7 & 8.7 & $\mathbf{2 6 . 0}$ & $\mathbf{3 2 . 0}$ \\
4-Test tekniklerini öğrenmek için gidiyorum & 4.0 & 9.3 & $\mathbf{1 5 . 3}$ & 36.0 & 35.3 \\
5- Boş zamanımı değerlendirmek için gidiyorum. & $\mathbf{2 4 . 7}$ & $\mathbf{1 8 . 0}$ & $\mathbf{1 7 . 3}$ & 18.7 & 21.3 \\
6-Hedeflediğim liseyi kazanabilmek için gidiyorum. & 4.7 & 1.3 & 6.0 & 16.0 & $\mathbf{7 2 . 0}$ \\
\hline Ortalama & 10.6 & 8.3 & 9.0 & 22.1 & 49.9 \\
\hline
\end{tabular}

1=kesinlikle katılmıyorum, 2=katılmıyorum, 3=Orta düzeyde katılıyorum, 4=katılıyorum, 5=kesinlikle katılıyorum. 
Tablo 2'de, öğrencilerin büyük çoğunluğunun (\%91.9) "iyi bir eğitim görmek için gidiyorum" maddesine katılıyorum ve kesinlikle katılıyorum şeklinde yanıt verdikleri görülmektedir. Benzer şekilde \%88'inin "hedeflediğim liseyi kazanabilmek için gidiyorum" maddesine katıllyorum ve kesinlikle katılıyorum yanıtını verdikleri anlaşılmaktadır. Öğrenciler "TEOG sınavından iyi puan alabilmek için gidiyorum" maddesine büyük oranda (\%83.3) katılıyorum ve kesinlikle katılıyorum seçeneklerini işaretledikleyerek görüşlerini bildirmişlerdir. Ayrıca öğrencilerin yarıya yakını (\%42.7) "boş zamanımı değerlendirmek için gidiyorum" maddesine kesinlikle katılmıyorum ve katılmıyorum şeklinde yanıt vermiştir. "Boş zamanımı değerlendirmek için gidiyorum" maddesinde ise düzeyler arasında dengeli bir dağılım görülmektedir.

\subsubsection{Etüt Merkezlerine Yönelik Görüş Ölçeği ilgi Boyutuna iliş̧kin Dağılımlar}

Öğrencilerin Etüt Merkezlerine Yönelik Görüş Ölçeğinin Illgi boyutuna ilişkin maddelere verdiklerin yanıtların yüzdelik dağılımları Tablo 3'de sunulmuştur.

Tablo 3. Illgi Boyutuna ilişskin Maddelerin Yüzdelik Dağılımları

\begin{tabular}{|c|c|c|c|c|c|}
\hline Maddeler & 1 & 2 & 3 & 4 & 5 \\
\hline $\begin{array}{l}\text { 9-Kendimi etüt merkezinde mutlu hissettiğim için } \\
\text { gidiyorum. }\end{array}$ & 16.0 & 18.7 & 18.7 & 22.0 & 24.7 \\
\hline 10-Etüt merkezini eğlenceli bulduğum için gidiyorum. & 24.0 & 20.0 & 17.3 & 25.3 & 13.3 \\
\hline $\begin{array}{l}\text { 11-Ailem çalıştığından dolayı derslerime yardımcı } \\
\text { olamadıkları için gidiyorum. }\end{array}$ & 34.7 & 22.7 & 15.3 & 11.3 & 16.0 \\
\hline $\begin{array}{l}\text { 12-Derslerimi tekrar etmek ve eksiklerimi gidermek } \\
\text { için gidiyorum. }\end{array}$ & 6.0 & 0.7 & 6.0 & 24.7 & 62.7 \\
\hline $\begin{array}{l}\text { 13-Öğretmenlerin daha ilgili olduğunu düşündüğüm } \\
\text { için gidiyorum. }\end{array}$ & 14.7 & 9.3 & 18.4 & 24.0 & 30.7 \\
\hline 14-Okulumdaki arkadaşlarım gittiği için gidiyorum. & 60.7 & 20.0 & 6.0 & 5.3 & 8.0 \\
\hline Ortalama & 26.0 & 15.2 & 13.6 & 18.7 & 25.9 \\
\hline
\end{tabular}

1=kesinlikle katımıyorum, 2=katımıyorum, 3=Orta düzeyde katılıyorum, 4=katılıyorum, 5=kesinlikle katılıyorum.

Tablo 3' de, öğrencilerin çoğu (\%87.4) "derslerimi tekrar etmek ve eksiklerimi gidermek için gidiyorum" maddesine katılıyorum ve kesinlikle katılıyorum şeklinde görüş bildirmiştir. Ayrıca öğrencilerin \%80.7'si "okulumdaki arkadaşlarım gittiği için gidiyorum" maddesini katılmıyorum ve kesinlikle katılmıyorum şeklinde yanıtlamıştır. Bazı öğrencilerin ise (\%18.4) "öğretmenlerin daha ilgili olduğunu düşündüğüm için gidiyorum" görüşüne orta düzeyde katıldıkları görülmektedir.

3.1.3. Etüt Merkezlerine Yönelik Görüş Ölçeği Gereksinim Boyutuna ilişkin Dağılımlar

Öğrencilerin etüt merkezlerine yönelik görüş ölçeğinin gereksinim boyutuna ilişkin maddelere verdiklerin yanıtların yüzdelik dağılımları Tablo 4'de sunulmuştur.

Tablo 4. Gereksinim Boyutuna ílişkin Maddelerin Yüzdelik Dağılımları

\begin{tabular}{|c|c|c|c|c|c|}
\hline Maddeler & 1 & 2 & 3 & 4 & 5 \\
\hline $\begin{array}{l}\text { 15-Evde tek başıma ders çalışamadığım için etüt } \\
\text { merkezine gidiyorum. }\end{array}$ & 27.3 & 14.7 & 20.0 & 21.3 & 16.7 \\
\hline $\begin{array}{l}\text { 16-Okulda anlamadığım dersleri telafi edebilmek için } \\
\text { gidiyorum. }\end{array}$ & 8.7 & 2.7 & 8.0 & 31.3 & 49.3 \\
\hline $\begin{array}{l}\text { 17-Rehberlik servisinden sınavlar hakkında bilgi } \\
\text { edinebildiğim için gidiyorum. }\end{array}$ & 21.3 & 13.3 & 27.3 & 16.0 & 22.0 \\
\hline $\begin{array}{l}\text { 18-Farklı öğretim teknikleriyle öğrenebilmek için } \\
\text { gidiyorum. }\end{array}$ & 9.3 & 6.0 & 15.3 & 26.0 & 43.3 \\
\hline 19-Çevremdeki herkes gittiği için gidiyorum. & 61.3 & 20.0 & 7.3 & 6.7 & 4.7 \\
\hline $\begin{array}{l}\text { 20-Ailem derslerim konusunda yetersiz kaldığı için } \\
\text { gidiyorum. }\end{array}$ & 27.3 & 21.3 & 19.3 & 14.7 & 17.3 \\
\hline Ortalama & 25.8 & 13.0 & 16.2 & 19.3 & 25.5 \\
\hline
\end{tabular}


Tablo 4'te, öğrencilerin büyük çoğunlunun (\%80.6) "okulda anlamadı̆̆ım dersleri telafi edebilmek için gidiyorum" maddesine katılıyorum ve kesinlikle katılıyorum şeklinde yanıt verdikleri anlaşılmaktadır. Benzer şekilde "çevremdeki herkes gittiği için gidiyorum" maddesine katılmıyorum ve kesinlikle katılmıyorum şeklinde görüş bildirenlerin oranı (\%81.3) yüksektir. Ayrıca öğrencilerin (\%27.3) "rehberlik servisinden sınavlar hakkında bilgi edinebildiğim için gidiyorum" maddesine çoğunlukla orta düzeyde katılıyorum şeklinde yanıt verdikleri görülmüştür.

\subsubsection{Etüt Merkezlerine Yönelik Görüş Ölçeği Önem Boyutuna ilişkin Dağılımlar}

Öğrencilerin Etüt Merkezlerine Yönelik Görüş Ölçeğinin Önem boyutuna ilişkin maddelere verdiklerin yanıtların yüzdelik dağılımları Tablo 5 'de sunulmuştur.

Tablo 5. Önem Boyutuna Illişkin Maddelerin Yüzdelik Dağılımları

\begin{tabular}{|c|c|c|c|c|c|}
\hline Maddeler & 1 & 2 & 3 & 4 & 5 \\
\hline $\begin{array}{l}\text { 7-Başarısız olduğum dersleri düzeltmek için } \\
\text { gidiyorum. }\end{array}$ & 5.3 & 5.3 & 4.0 & 29.3 & 56.0 \\
\hline 8-Eğitimdeki hedeflerime ulaşabilmek için gidiyorum. & 3.3 & 1.3 & 4.0 & 19.4 & 72.0 \\
\hline 21-Annem istediği için gidiyorum. & 45.3 & 25.4 & 12.7 & 5.3 & 11.3 \\
\hline 22-Başarıı biri olmadığım için gidiyorum. & 36.7 & 17.4 & 17.3 & 13.3 & 15.3 \\
\hline $\begin{array}{l}\text { 23-Okulda verilen dersleri yetersiz bulduğum için } \\
\text { gidiyorum. }\end{array}$ & 26.7 & 14.7 & 19.3 & 18.0 & 21.3 \\
\hline $\begin{array}{l}\text { 24-Sınıflarda okuldan daha az öğrenci olduğu için } \\
\text { gidiyorum. }\end{array}$ & 46.7 & 23.4 & 15.3 & 6.7 & 8.0 \\
\hline Ortalama & 27.3 & 14.5 & 12.1 & 15.3 & 30.6 \\
\hline
\end{tabular}

1=kesinlikle katılmıyorum, 2=katılmıyorum, 3=Orta düzeyde katılıyorum, 4=katılıyorum, 5=kesinlikle katılıyorum.

Tablo 5'te öğrencilerin çoğunun (\%91.4) "eğitimdeki hedeflerime ulaşmak için gidiyorum" maddesini katılıyorum ve kesinlikle katılıyorum şeklinde işaretlediği görülmektedir. Öğrencilerin \%85.3'ü "başarısız olduğum dersleri düzeltmek için gidiyorum" maddesini katılıyorum ve kesinlikle katılıyorum şeklinde işaretlemiştir. Öğrencilerin \%70.1'i "sınıflarda okuldaki sınıflardan daha az öğrenci olduğu için gidiyorum" maddesine katılmıyorum ve kesinlikle katılmıyorum şeklinde yanıt vermişlerdir. \%17.3 ise "başarılı biri olmadığım için gidiyorum" maddesine orta düzeyde katılıyorum görüşünü bildirmiştir. "Okulda verilen dersleri yetersiz bulduğum için gidiyorum" maddesine orta düzeyde katılanların oranı ise \%19.3 olarak belirlenmiştir.

\section{2 İkinci Alt Probleme iliş̧kin Bulgular}

Ortaokul öğrencilerinin etüt merkezlerine yönelik görüşlerinin cinsiyetlerine göre farklılık gösterip göstermediğini ortaya koymak amacıyla yapılan bağımsız t-testi sonuçları Tablo 6' da verilmiştir.

Tablo 6. Öğrencilerin Cinsiyetlerinin Boyutlara Göre Karşılaştırılması

\begin{tabular}{|c|c|c|c|c|c|c|c|}
\hline Boyutlar & Cinsiyet & $\mathbf{N}$ & $\bar{X}$ & $S$ & Sd & $t$ & $\mathbf{p}$ \\
\hline \multirow[t]{2}{*}{ Önem } & $\mathrm{KIZ}$ & 75 & 3.00 & .60 & .120 & -1.141 & .256 \\
\hline & Erkek & 75 & 3.14 & .84 & & & \\
\hline \multirow[t]{2}{*}{ illgi } & $\mathrm{KIZ}$ & 75 & 3.05 & .79 & .140 & .119 & .906 \\
\hline & Erkek & 75 & 3.03 & .91 & & & \\
\hline \multirow[t]{2}{*}{ Beklenti } & $\mathrm{KIZ}$ & 75 & 4.01 & .67 & .432 & 1.277 & .203 \\
\hline & Erkek & 75 & 3.84 & .92 & & & \\
\hline \multirow[t]{2}{*}{ Gereksinim } & $\mathrm{KIZ}$ & 75 & 3.02 & .79 & .195 & -.489 & .625 \\
\hline & Erkek & 75 & 3.08 & .81 & & & \\
\hline
\end{tabular}

Tablo 6'ya göre öğrencilerin görüş ölçeğindeki beklenti boyutu [t(150)= $-1.141, \mathrm{p}>.05]$, gereksinim boyutu [t(150)=-0.625, $\mathrm{p}<.05]$, önem boyutu $[\mathrm{t}(150)=0.119, \mathrm{p}<.05]$ ve ilgi boyutuna $[\mathrm{t}(150)=0.119$, $\mathrm{p}<.05$ ] ilişkin görüşlerinin cinsiyetlerine göre farklılaşmadığı görülmektedir.

\section{3 Üçüncü Alt Probleme ilişkin Bulgular}

Öğrencilerin etüt merkezlerine yönelik görüş ölçeğinin boyutlarına ilişkin ortalamalarının sınıf düzeylerine göre değişimi Tablo 7'de sunulmuş, dağılıma ilişkin grafiksel gösterim ise Şekil 1'de verilmiştir. 
Tablo 7. Boyutlara iliş̧kin Görüş Ortalamalarının Sınıf Düzeyine Göre Dağılımı

\begin{tabular}{llllll}
\hline \multirow{2}{*}{$\begin{array}{l}\text { Sınıf } \\
\text { Düzeyi }\end{array}$} & \multirow{N}{*}{} & Beklenti & Gereksinim & Önem & Ilgi \\
\cline { 3 - 6 } & & $\overline{\boldsymbol{X}}(\mathrm{S})$ & $\overline{\boldsymbol{X}}(\mathrm{S})$ & $\overline{\boldsymbol{X}}(\mathrm{S})$ & $\overline{\boldsymbol{X}}(\mathrm{S})$ \\
\hline 5.sınıf & 15 & $3.74(0.72)$ & $2.84(1.01)$ & $2.90(0.61)$ & $2.94(1.11)$ \\
6. sınıf & 52 & $3.82(0.83)$ & $3.08(0.86)$ & $3.02(0.78)$ & $2.99(0.78)$ \\
7. sınıf & 83 & $4.02(0.81)$ & $3.07(0.72)$ & $3.13(0.72)$ & $3.09(0.85)$ \\
\hline
\end{tabular}

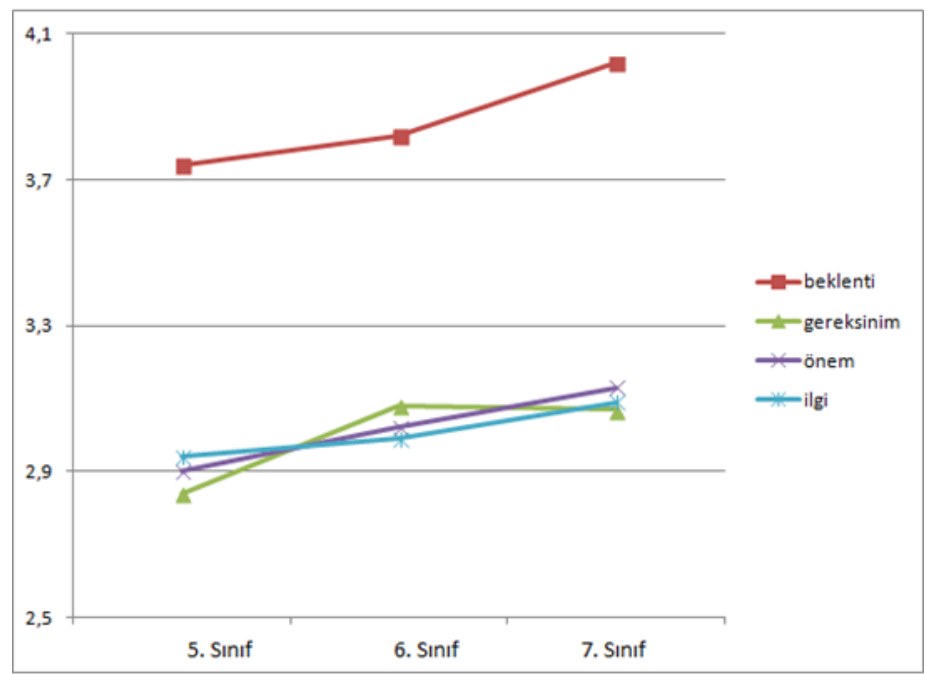

Şekil 1. Boyutlara ilişkin Görüş Ortalamalarının Sınıf Düzeyine Göre Değişimi

Tablo 7 ve Şekil 1 birlikte incelendiğinde; gereksinim, önem ve ilgi boyutlarına ilişkin ortalamalarının birbirine çok yakın olduğu anlaşılmaktadır. Bununla birlikte sınıf düzeyi arttıkça, tüm boyutlarda ortalama değerlerinde arttığı görülmektedir. Beklenti boyutunda ise diğer boyutlardan daha yüksek bir ortalama göze çarpmaktadır. Tüm sınıf düzeylerinde, öğrencilerin etüt merkezlerinden beklentilerinin diğer boyutlara göre daha yüksek olduğu belirtilebilir.

Öğrencilerin, etüt merkezlerine yönelik görüşlerinin sınıf düzeylerine göre farklılık gösterip göstermediğini ortaya koymak amacıyla tek yönlü varyans analizi yapılmıştır. Analiz sonuçları Tablo 8 'de sunulmuştur.

Tablo 8. Öğrencilerin sınıf düzeylerinin boyutlara göre karşılaştırılması.

\begin{tabular}{|c|c|c|c|c|c|c|c|}
\hline & $\begin{array}{l}\text { Varyansın } \\
\text { Kaynağı }\end{array}$ & $\begin{array}{l}\text { Kareler } \\
\text { Toplamı }\end{array}$ & Sd & $\begin{array}{l}\text { Kareler } \\
\text { Ortalaması }\end{array}$ & $\mathbf{F}$ & $\mathbf{p}$ & $\begin{array}{l}\text { Anlamlı } \\
\text { Fark }\end{array}$ \\
\hline \multirow{3}{*}{ Beklenti } & GA & 1.916 & 2 & 0.958 & 1.448 & 0.289 & \\
\hline & $\mathrm{Gi}$ & 97.217 & 147 & 0.661 & & & ------ \\
\hline & Toplam & 99.133 & 149 & & & & \\
\hline \multirow{3}{*}{ Gereksinim } & $\mathrm{GA}$ & 0.742 & 2 & 0.371 & 0.570 & 0.567 & \\
\hline & $\mathrm{Gi}$ & 95.687 & 147 & 0.651 & & & ------- \\
\hline & Toplam & 96.429 & 149 & & & & \\
\hline \multirow{3}{*}{ Önem } & $\mathrm{GA}$ & 0.944 & 2 & 0.472 & 0.866 & 0.423 & \\
\hline & $\mathrm{Gi}$ & 80.181 & 147 & 0.545 & & & ------- \\
\hline & Toplam & 81.125 & 149 & & & & \\
\hline \multirow{3}{*}{ İlgi } & GA & 0.480 & 2 & 0.240 & 0.323 & 0.724 & \\
\hline & $\mathrm{Gi}$ & 109.104 & 147 & 0.742 & & & -------- \\
\hline & Toplam & 109.584 & 149 & & & & \\
\hline
\end{tabular}

Tablo 8'de sunulan analiz sonuçlarına göre, öğrencilerin etüt merkezi görüş ölçeğinin beklenti $[F(2,147)=1.448, p>.05]$, gereksinim $[F(2,147)=0.570, p>.05]$, önem $[F(2,147)=0.866, p>.05]$ ve ilgi boyutlarında $[F(2,147)=0.724, p>.05]$, sınıf düzeylerine göre bir farklılaşma olmadığı görülmektedir. 


\section{TARTIŞMA ve SONUÇ}

Bu çalışmada ortaokul 5, 6 ve 7. sınıf öğrencilerinin etüt merkezlerine yönelik görüşleri beklenti, ilgi, gereksinim ve önem değişkenlerine göre belirlenmeye çalışılmıştır. Bu amaç doğrultusunda elde edilen sonuçlara yer verilmiş ve etüt merkezleri ile ilgili az sayıda olan literatürdeki çalışmalar bu çalışmadaki sonuçlarla ilişkilendirilmiştir.

Öğrencilerin görüş ölçeğinde vermiş olduğu cevaplar incelendiğinde, beklenti boyutunda iyi bir eğitim görmek ve TEOG sınavından yüksek puan alabilmek için gittikleri görüşüne katıldıkları görülmektedir. Yeşilyurt'un (2008) yaptığı çalışmada da, lise öğrencileri dershaneye gitme nedeni olarak üniversite giriş sınavını göstermişlerdir. Çalışmaya 8. Sınıf öğrencilerinin katılmamasına rağmen 5, 6 ve 7. sınıf öğrencilerinin TEOG sınavlarına yönelik farkındalık geliştirdikleri anlaşılmaktadır. Çalışmanın ilk bölümünde yer alan açık uçlu maddelere yönelik "etüt merkezlerine boş zamanlarımı değerlendirmek için gidiyorum" şeklindeki görüşü genellikle anne ve babası çalışan öğrenciler belirtmiştir. Çünkü anne ve babası çalışan çocukların birçoğu evde tek başlarına kalmaması ve derslerinde başarı gösterebilmesi için aile baskı durumuyla etüt merkezlerine gittikleri anket sonuçlarıyla elde edilmiştir. Literatürde de buna paralel olarak yapılan bir çalışmada, öğrencilerin etüt merkezine gitmelerindeki en büyük etkenin aile olduğu belirtilmektedir (Şimşek ve Şimşek, 2015).

Öğrencilerin çoğunun ilgi boyutunda derslerini tekrar etmek ve eksiklerini gidermek amacıyla etüt merkezlerine geldikleri, ayrıca öğrencilerin etüt merkezlerini tercihlerinde sınıf arkadaşlarının bu merkezlere gitmesinden etkilenmedikleri belirlenmiştir. Ayrıca gereksinim boyutunda da ailesinin dersler konusunda yetersiz kaldığını ifade eden benzer sonuçlar vardır. Bu sonuçla ilgili olarak, günümüzde birçok veli geçimini sağlamak için çalışmakta ve çocuklarıyla ilgilenememektedirler. Bu nedenle aileleler çocuklarıyla ilgilenen birilerinin olması için onları kurslar ve etüt merkezleri gibi yerlere yönlendirmektedirler. Böylelikle çocuklarının zamanlarını boşa geçirmeleri yerine farkı alanlarda gelişebileceklerini düşünmektedirler. Öğrencilerin anne ve babalarının çalışıyor olması, öğrencilere ders konusunda yardımcı olamamaları gibi nedenlerle etüt merkezlerini tercih ettikleri ifade edilmektedir (URL 4; Ünsal ve Korkmaz, 2016). Literatürdeki bir çalışmada, ailelerin çeşitli nedenlerle, çocukların ihtiyaç duyduğu eğitsel desteği sağlama konusunda ya isteksiz ya da yetersiz oldukları ve bu durumunda, çocuğun aleyhine olduğu ve çocuklarının daha fazla zarar görmemeleri için çeşitli arayışlara giriştiğinden söz edilmektedir. Bu nedenle ailelerin, çocuklarına hem başarısız oldukları konulara yönelik eğitsel destek, hem de okul dışındaki zamanlarını farklı etkinliklerle değerlendirme imkânı veren etüt merkezlerine yöneldikleri belirtilmiştir (Şimşek ve Şimşek, 2015). Öğrencilerin bir kısmı da öğretmenlerinden ilgi gördükleri için etüt merkezlerine gittiklerini ifade etmişlerdir.

Öğrencilerin çoğunun gereksinim boyutunda, okulda anlamadıkları dersleri tekrar edebilmek için etüt merkezlerini tercih ettikleri ifade edilebilir. Öğrenciler, etüt merkezlerine çevrelerindeki herkes gittiği için gitmediklerini ifade etmişlerdir. Varılan sonuçlardan yola çıkılarak bu öğrencilerin genellikle etüt merkezlerinin okula yardımcı olması bağlamında tercih edildiği söylenebilir. Ayrıca öğrencilerin rehberlik servisinden sınavlar hakkında bilgi edinebilmek için gittiklerini de belirtmişlerdir.

Öğrencilerin çoğunun önem boyutunda eğitimdeki hedeflerine ulaşmak ve başarısız oldukları dersleri düzeltmek için etüt merkezlerini tercih ettikleri belirlenmiştir. Ayrıca öğrencilerin sınıflarda okuldan daha az öğrenci olduğu için etüt merkezlerini tercih ettikleri söylenebilir. Ancak bu oran oldukça düşüktür. Başarılı olmadıkları ve okulda verilen dersleri yetersiz buldukları için gittiklerini belirten öğrencilerin oranı ise dikkat çekici düzeydedir. Özel etüt merkezlerinde çalışan öğretmenlere göre, öğrencilerin etüt merkezlerine gelme nedenlerinin başında okuldaki sınıf mevcutlarının fazlalığı, okullarında ders dinlemekte zorlandıkları, okul da anlatılan konuların merkezi sınav sistemi için yetersiz olması ve ders programlarının merkezi sınav sorularına yönelik düzenlenmemesi bulunmaktadır (Baştürk ve Doğan, 2010). Velilerin çocuklarını etüt merkezlerine yollamasının başlıca sebepleri arasında etüt merkezlerinin öğrencilerin çalışma isteklerini artırması 
ve okullardaki kalabalık sınıflarda öğrencilerin konuları anlamada güçlük çekmesi, okullarda verilen derslersin TEOG merkezi sınav sistemi için yetersiz görülmesi yer almaktadır (Açıkgöz, 2007).

Özel sektör girişimcileri, öğrenci ve ailelerin beklentilerini dershane ve etüt merkezleri açarak karşılamaya çalışmaktadır. Şirin (2000) öğrencilerin, özel dershaneye zayıf oldukları derslerden yetişmekle birlikte test tekniği kazanma, bir üst eğitim kurumuna girme sınavını kazanmak için okuldaki eğitimin yetersiz olarak algılamalarından dolayı dershaneyi seçtiklerini ifade etmektedir. Kuther, Sherman ve Williams'a (1986) göre de, özel eğitim kurumları genellikle kamu okullarının kapasite yetersizliği, nitelik yetersizliği, farklı eğitim alma isteği sebepleriyle gelişme göstermektedir. Özellikle fiziki koşullar ve merkezi sınav kaygısı konusunda, literatürün çalışmanın sonuçlarını desteklediği anlaşılmaktadır.

Çalışmada öğrencilerin etüt merkezleri hakkındaki görüşlerinin cinsiyetlerine göre farklılaşmadığı ortaya konulmuştur. Şirin (2000) erkek öğrencilerin dershaneye gitme kararını verirken daha çok arkadaşlarının etkisinde kaldıklarını, kız öğrencilerin ise ailesinin etkisinde kaldığını yaptı̆̆ı çalışmayla ortaya koymuştur. Bu çalışmanın daha küçük yaştaki öğrencilerle yürütülmüş olmasının bu farklılı̆ı desteklemediği ifade edilebilir.

Çalışmada sınıf düzeylerinde istatistiksel olarak anlamlı bir farklılık çıkmasa da, öğrencilerin etüt merkezleri hakkındaki görüşlerinin betimsel olarak sınıf düzeyi arttıkça, artış gösterdiği belirlenmiştir. Bununla birlikte boyut ortalamaları karşılaştırıldığında beklenti boyutunun diğer boyutlardan belirgin şekilde daha yüksek bir ortalamaya sahip olduğu göze çarpmaktadır. Tüm sınıf düzeylerinde, öğrencilerin etüt merkezlerinden beklentilerinin, etüt merkezlerine duydukları ilgi, gereksinim ve etüt merkezlerine verdikleri önemden daha yüksek olduğu şeklinde yorumlanabilir. Bu durumun öğrencilerin içinde bulundukları rekabet ortamından kaynaklandığı belirtilebilir. Öğrenciler etüt merkezlerini okulda veya merkezi sınavlarda başarılı olmak için çoğunlukla tercih etmektedir. Özellikle merkezi sınavlar sonrasındaki bağıl değerlendirme sistemi, öğrenciler arasındaki rekabeti kaçınılmaz hale getirmekte bu da etüt merkezlerine yönelik beklentiyi artırmaktadır. Öğrenciler arasındaki rekabetin, onları okul dışında alternatif kurslar aramaya yönlendirdiği belirtilmektedir (Yeşilyurt, 2008).

\section{5. ÖNERILER}

Çalışmada, öğrencilerin etüt merkezlerine yönelik görüşlerinin farklı olduğu ve çeşitli değişkenlerden etkilenebileceği ortaya konulmuştur. Bu çalışmada dikkate alınmayan aile ve sosyal yaşam vb. başka değişkenler kullanılarak benzer çalışmalar yürütülebilir. Etüt merkezleri okul derslerine destek sağlayan, öğrencilerin boş zamanlarını dolduran, merkezi sınavlara hazırlayan ve öğrencilerin rekabet gücünü artıran kuruluşlar olarak değerlendirilebilir. Ancak bazı durumlarda okuldan daha nitelikli öğretim faaliyetleri sağlaması dolayısıyla okula alternatif olarak görülmektedir. Özellikle nitelikli eğitime ulaşabilmek amacıyla, arayış içine giren ailelerin bu merkezleri tercih ettikleri görülmektedir. Bu çalışmadan ortaya konulan, etüt merkezini tercih etme gerekçelerinin büyük çoğunluğunun sistemsel problemlerden kaynaklandığı anlaşılmaktadır. Bunun yanı sıra, çalışan anne-babaların, çocuklarını okul dışındaki boş zamanlarını geçirmeleri için etüt merkezlerine yönlendirdikleri anlaşılmaktadır. Etüt merkezlerinde sadece akademik derslere yönelik eğitim verilmesi dolayısıyla, bu durumdaki çocukların sosyal, sanatsal veya sportif faaliyetlere yönlendirilmesi önerilebilir.

\section{Kaynakça}

Açıkgöz, K. Ü. (2007). Etkili Öğrenme ve Öğretmen. (7. Baskı). İzmir: Kanyılmaz Matbaası.

Akkoyunlu, B. (1998). Eğitimde Teknolojik Gelişmeler. B. Özer (Ed.). Çağdaş eğitimde yeni teknolojiler içinde (s.1-14). Eskişehir: Anadolu Üniversitesi Yayınları.

Aslan, M. (2004). Eğitim sisteminin kapanmayan yarası yükseköğretime geçiş. Sosyal Bilimler Enstitüsü Dergisi, 16(1), 37-51. 
Baştürk, S. (2003). L'enseignement des mathématiques en Turquie: le cas des fonctions au lycée et au concours d'entrée à l'université. Paris: IREM de Paris 7.

Baştürk, S. ve Doğan, S. (2010). Lise Öğretmenlerinin Özel Dershaneler Hakkındaki Görüşlerinin Incelenmesi. Uluslararası insan Bilimleri Dergisi, 7(2), 135-157.

Büyükköse, F. (2010). Dershane seçiminde etkili olan faktörlerin belirlenmesi. Yayınlanmamış yüksek lisans tezi, İstanbul Üniversitesi Fen Bilimleri Enstitüsü, İstanbul.

Çeken, R. (2009). Model Öğretmen Olabilmek. Türkiye Özel Okullar Birliği Dergisi, 2(10), 18-20.

Duran, A., Düzgün, O. ve Duran, S. (2014). Sosyo-ekonomik Düzeyleri Farklı Öğrenci Velilerinin Özel Dershanelere Yönelik Tutumlarının İncelenmesi. Eğitim Bilimleri Araştırmaları Dergisi, 4 (Özel Sayı 1), 171-185.

Gümüş, A. (2014). Dershane Düzenlemesi Tartışmalarına Eğitsel Bir Bakış (Politika Notu No. 2014/03). İstanbul: Ilmi Etüdler Derneği.

Kanat, Ö. (2004). Türk-Alman genel eğitim sistemlerinin karşıllaştırılması. Yüksek lisans tezi, Marmara Üniversitesi Fen Bilimleri Enstitüsü, İstanbul.

Köse, E. (2013). Eğitim kurumlarında gerçekleştirilen ders dışı etkinliklerin sınıflandırılmasına yönelik bir öneri. Uluslararası Türkçe Edebiyat Kültür Eğitim (TEKE) Dergisi, 2(2), 336-353.

Kutner, M. A., Sherman, J. D. ve Williams, M. F. (1986). Federal Policies For Private. New York: Private Educatian (s. 83).

Lawshe, C. H. (1975) A Quantitative Approach to Content Validity. Personnel Psychology. 28, 563575.

Morgil, I.., Yılmaz, A. ve Geban, O. (2001). Özel dershanelerin üniversiteye girişte öğrenci başarısına etkileri. Hacettepe Üniversitesi Eğitim Fakültesi Dergisi, 21, 89-96.

Okur, M. ve Dikici, R. (2004). Özel Dershaneler ile Devlet Okullarının Kartezyen Çarpım, Analitik Düzlem ve Bağıntı Konularındaki Bilgi ve Becerileri Kazandırma Düzeylerinin Değerlendirilmesi. Kastamonu Eğitim Dergisi, 12(2), 417-426.

Şimşek, H. ve Şimşek, S. (2015). Ailenin Dönüşümü ve Aile Sorumluluğu Bağlamında Etüt Merkezlerini Yeniden Düşünmek. Kastamonu Eğitim Dergisi, 23(1), 365-384.

Şirin, H. (2000). Eğitim Sisteminde Özel Dershaneler. Kuram ve Uygulamada Eğitim Yönetimi Dergisi, 2, 387- 410.

Tansel, A. ve Bircan, F. (2004). Private tutoring expenditures in Turkey. Turkish Economic Association Discussion Paper, Alıntılanma adresi: http://www.tek.org.tr/dosyalar/A-TANSELMAY-04.pdf Alıntılanma tarihi: 30.07.2017.

Türkoğlu, A. (2011). 100 Soruda Eğitim Bilimine Giriş. İmir: Teknofset Matbaacılık.

URL1. http://www.newgokturk.com/egitim-sistemimizde-etut-merkezlerinin-yeri-makale,710.html.

URL 2. http://www.hurriyet.com.tr/ozel-etut-merkezleri-kapatiliyor-40364423

URL 3. http://www.egitimajansi.com/haber/okul-ile-dershanenin-islevleri-birbirinden-farkli-haberi21417h.html

URL 4. http://www.egitimalver.com/etut-merkezlerinin-ogrencilere-ve-velilere-sundugu-faydalaridegerlendirdik/blog/?id=18.

Ünsal, S. ve Korkmaz, F. (2016). Destekleme ve Yetiştirme Kurslarının İşlevlerine Iliş̧kin Öğretmen Görüşlerinin İncelenmesi. KSÜ Sosyal Bilimler Dergisi, 13(2), 87-118.

Veneziano L. ve Hooper J. (1997). A Method for Quantifying Content Validity of Health-Related Questionnaires. American Journal of Health Behavior, 21(1), 67-70.

Yeşilyurt, S. (2008). Üniversiteye Giriş Sınavına Hazırlanan Öğrencilerin Dershaneleri Tercih Etme Sebepleri ve Dershanelerdeki Biyoloji Öğretiminin Durumu Üzerine Bir Çalışma. Türk Fen Eğitimi Dergisi, 5(2), 95-109.

Yurdugül, H. (2005). Ölçek geliştirme çalışmalarında kapsam geçerliği için kapsam geçerlik indekslerinin kullanılması. XIV. Eğitim Bilimleri Kurultayı, 28-30 Eylül, Pamukkale Üniversitesi, Denizli. 


\section{Extended Summary}

In Turkey, the courses called "Private Tutoring Centers" were established in accordance with the regulation of the Ministry of National Education Private Tutoring Centers established in 2011. Although Private Tutoring Centers are not defined as private educational institutions where various activities that help students with their lessons, homework and projects are carried out according to their interests, requests, and skills, they offer different lessons and practice opportunities to enrolled students from primary school to high school levels. In addition to training courses, "Tutoring Centers", which have become popular recently, can be seen as a private and paid alternative to these courses. Especially designed for children whose parents work all day and who receive double shift schooling, tutoring centers have expanded their field of activity as they have become more widespread. These centers also conduct activities to prevent students from failing in their lessons, help them with their lessons, homework, projects, and exams.

Tutoring centers which were included in our education system in 2011 were closed in 2017 and 2006 tutoring centers were entitled to the right of transformation with the change made in Law No. 5580 on Private Education Institutions with the statutory decree no. 687. The expression and definition of "student tutoring centers" in Law No. 5580 on Private Education Institutions was abolished and the expression of "social activity centers" was added instead. With the statutory decree, it was allowed to open "social activity centers", which were not in the law before. It has been planned that social, cultural and artistic activities of the students can be carried out in these centers. It is seen that this decision will not allow primary and secondary school students to attend any supplementary courses out of school. It is seen that the opinions put forward about tutoring centers reflect the perspectives of adults, rather than those of students. In this context, it is envisaged that researching the opinions of the students who attend private tutoring centers will contribute to the related literature. In addition, this study is regarded as important since it aims to reveal how these tutoring centers, which are about to be closed, meet the needs of students and parents and since new formations (social activity centers, etc.) that will meet this need will be structured with the results to be obtained. In this study, it is aimed to examine the opinions of primary school students about tutoring centers and to determine whether these opinions differ according to gender and grade.

To this end, answers to the following research questions are sought:

1. How are secondary school students' views on tutoring centers?

2. Do secondary school students' views on tutoring centers differ according to gender?

\section{Do secondary school students' views on tutoring centers differ according to grade?}

The study conducted with descriptive model was carried out in two stages. In the first stage, a questionnaire consisting of open-ended items was applied to 50 students trained in a tutoring center in Istanbul in the academic year of 2016-2017. In the second stage, a scale form was developed using the items obtained from the questionnaire and applied to the participants. The samples of the research were collected from 6th and 7th grades in the tutoring center in Rize in the 2016-2017 academic year, 45 in the tutoring center in Çayeli district, 45 in the 5th, 6th and 7th grades and 6,7 150 students from 48 classrooms participated. The sample of the research consists of a total of 150 students receiving education in tutoring centers in the 2016-2017 academic year. 57 students in the $6^{\text {th }}$ and $7^{\text {th }}$ grades are trained in a tutoring center in Rize, 45 students in the $5^{\text {th }}$ $6^{\text {th }}$, and $7^{\text {th }}$ grades in Çayeli, and 48 students in the $6^{\text {th }}$ and $7^{\text {th }}$ grades in Istanbul, Küçükçekmece. $50.0 \%$ of the participating students are female and $50.0 \%$ are male.

A questionnaire consisting of open-ended questions was prepared in order to determine the opinions of secondary school students about tutoring centers. The questionnaire was applied to 50 students enrolled in a tutoring center in Istanbul in the 2016-2017 academic year. To learn students' reasons for choosing tutoring centers and opinions on tutoring centers, some questions were asked to them in the questionnaire. In the light of the data obtained from this questionnaire, 
5 point likert scale "Opinion Scale on Tutoring Centers" including 24 items was formed. Scoring of the items in the scale is out of 5. The options of the scale are as follows: (1) I never agree, (2) I do not agree, (3) I am undecided, (4) I agree, (5) I completely agree. By taking the expert opinion, 24 items of the scale were divided into four sub-dimensions as "importance, need, expectation and interest". Internal consistency coefficient for the whole scale was calculated as $a=0.87$. Other internal consistency coefficients were calculated as $\alpha=0.74, a=0.59 a=0.70$ and $a=0.65$ for the sub dimensions of expectation, importance, interest and need, respectively.

In the study, it was revealed that the opinions of the students about tutoring centers do not differ according to gender. Also, it was determined that the opinions of the students about tutoring centers increase relatively as the class level increases. However, this increase is not statistically significant. When the size averages are compared, it is seen that the sub-dimension of expectation has a bit higher average than the others. It can be interpreted that the students' expectations from tutoring centers are a bit higher than the interest they have for the tutoring centers, need and importance they attach to these tutoring centers in all grades. It can be said that this situation is caused by the competition environment in which the students are living.

In the study, it was found that the opinions of the students about tutoring centers can be influenced by different contexts. Tutoring centers can be considered as the institutions which provide support for school courses, prepare students for central exams, increase the competitive power of students, and where students spend their leisure time. However, these tutoring centers are considered as an alternative to school because they provide more qualified teaching activities in some cases. It is seen that the families who are seeking to reach qualified education prefer these centers. According to the results of the study, it is understood that the vast majority of reasons for choosing tutoring centers are due to systematic problems and inadequate education in schools. 